\title{
Accuracy of sonographic criteria in the decision for surgical treatment in infantile hypertrophic pyloric stenosis
}

\author{
Jerzy Niedzielski ${ }^{1}$, Artur Kobielski², Jan Sokal'2, Marek Krakós ${ }^{1}$
}

1Department of Paediatric Surgery and Urology, University School of Medicine in Lodz, University Children's Hospital No. 4, Lodz, Poland

2Department of Radiology, University Children's Hospital No. 4, Lodz, Poland

Submitted: 14 May 2010

Accepted: 1 June 2010

Arch Med Sci 2011; 7, 3: 508-511

DOI: 10.5114/aoms.2011.23419

Copyright ( 2011 Termedia \& Banach

\section{Abstract}

Introduction: Abdominal ultrasonography has replaced barium studies in establishing the diagnosis in difficult cases of infantile hypertrophic pyloric stenosis (IHPS). The aim of this retrospective study was to establish sonographic criteria of qualification for surgical treatment in children with IHPS.

Material and methods: Hundred and fifteen infants (98 boys and 17 girls) with suspected IHPS were treated between 2000 and 2009. Pyloric muscle thickness, pyloric diameter and pyloric length were measured in US scans in all patients. Results were compared with US results of 19 infants with negative diagnosis and 29 children of the reference group.

Results: Diagnosis of IHPS was confirmed by US examination in 96 children $(83.5 \%)$. There were 86 boys in the group with male prevalence $8.6: 1$. The remaining 19 infants (16.5\%) had a negative ultrasound. The mean PL (20.89 vs. 12.73), PMT (5.41 vs. 2.24), and PD (14.1 vs. 7.42) differed significantly between patients with and without pyloric stenosis $(p<0.0001)$. The mean PL (12.34), PMT (2.2), and PD (7.48) in the reference group did not differ statistically from values obtained in patients with negative IHPS diagnosis and were significantly lower than in children from the IHPS group ( $p<0.0001)$. US imaging had a sensitivity of $98 \%$, specificity of $100 \%$, with a positive and negative predictive value of $100 \%$ and $90 \%$ respectively.

Conclusions: This study confirmed that ultrasonography is the first choice of diagnostic method in an infant with suspected hypertrophic pyloric stenosis. In cases with an uncertain clinical diagnosis of IHPS the examination can be easily repeated.

Key words: infantile hypertrophic pyloric stenosis, ultrasonography, pyloric length, pyloric diameter, pyloric muscle thickness.

\section{Introduction}

Overall incidence of infantile hypertrophic pyloric stenosis (IHPS) in Europe assessed by EUROCAT (registries of congenital malformations) was 2.0 per 1000 live births (LB), ranging from 0.86 to 3.96 per 1000 LB [1]. The rate of IHPS in the USA ranges from 1.7 to 2.4 per 1000 LB $[2,3]$ and in the UK from 1.4 to 4.4 per 1000 LB $[4,5]$. Infantile hypertrophic pyloric stenosis occurs predominantly in boys compared with girls $(4.2: 1)$, and in Whites compared with Blacks $(2.8: 1)$ and compared with Asians $(5: 1)[3,6]$.

\author{
Corresponding author: \\ Prof. Jerzy Niedzielski MD, PhD \\ Department of Paediatric \\ Surgery and Urology \\ University Children's \\ Hospital No. 4 \\ 91-738 Lodz, 36/50 Sporna \\ Poland \\ E-mail: \\ jerzy.niedzielski@umed.lodz.pl
}


The exact cause of IHPS is still poorly understood, although more than two hundred years have passed since it was first described [7]. Luckily pyloromyotomy, introduced by Ramstedt in 1912, is an operation that has proved to be curative and without any modification has been accepted worldwide as the procedure for IHPS for a 100 years now [8]. Non-bilious vomitus is the initial symptom of the disease. Diagnosis is established by palpating the olive-shaped, firm pyloric muscle mass and abdominal ultrasonography. Abdominal ultrasonography has replaced barium studies in establishing the diagnosis in difficult cases of hypertrophic pyloric stenosis and has become the diagnostic method of choice for IHPS over the last 20 years [9-11].

The aim of this retrospective study was to find sonographic criteria for the necessity of surgical treatment of IHPS and to assess the sensitivity of ultrasound imaging in the diagnosis of the disease.

\section{Material and methods}

The medical records of 115 infants with suspected IHPS treated in the University Children's Hospital No. 4 in Lodz, Poland between 2000 and 2009 were reviewed retrospectively and analysed. There were 98 boys and 17 girls, at median age of 40 days (range: 13 to 111 days) in the group.

All children had ultrasound imaging (US) with details of the pylorus. Measurements of the pyloric muscle thickness (PMT), pyloric diameter (PD) and pyloric length $(\mathrm{PL})$ were taken from a longitudinal scan of the pylorus. Results obtained in the IHPS group were compared with US data obtained in infants with negative diagnosis and with measurements in the reference group. The reference group consisted of 29 infants (19 boys and 10 girls), at median age of 56 days (range: 15 to 107 days) hospitalized for other diseases such as pneumonia, urological problems or abdominal hernias, with no clinical manifestation of pyloric stenosis (vomiting).

The accuracy of the US procedure was related to the finally established diagnosis. Statistical analysis was performed with Student's t-test.

\section{Results}

Diagnosis of IHPS was confirmed by US examination in 96 out of 115 children (83.5\%). There were 86 boys and 10 girls, aged 13 to 111 days in the IHPS group, with male prevalence $8.6: 1$. The remaining 19 of 115 infants (16.5\%) had a negative ultrasound and were disqualified from surgery (Table I). Conservative treatment led to resolution of vomiting in these children, which proved that the sonographic result was in agreement with the clinical outcome.

The mean pyloric muscle thickness (PMT 5.41 vs. 2.24), pyloric diameter (PD 14.1 vs. 7.42), and pyloric length (PL 20.89 vs. 12.73) differed significantly between patients with and without pyloric stenosis $(p<0.0001)$ (Table II). The PMT value was never

Table I. Clinical manifestations in the studied groups of infants

\begin{tabular}{|lccccc|}
\hline Groups of patients & No. of patients (\%) & M & F & M/F rate & Age [days], median (range) \\
\hline Infants with vomiting & 115 & 94 & 21 & $4.5: 1$ & $40(13-111)$ \\
\hline - Qualified for operation & $96(83.5 \%)$ & 86 & 10 & $8.6: 1$ & $40(13-111)$ \\
\hline - Treated conservatively & $19(16.5 \%)$ & 8 & 11 & $1: 1.3$ & $42(19-99)$ \\
\hline Controls & 29 & 19 & 10 & $1.9: 1$ & $53.8(15-107)$ \\
\hline
\end{tabular}

$M$ - male, $F$-female

Table II. Sonographic data

\begin{tabular}{|c|c|c|c|c|}
\hline \multirow{2}{*}{$\begin{array}{l}\text { US parameters [mm[] } \\
\text { Mean value (SD) }\end{array}$} & \multicolumn{3}{|c|}{ Patients } & \multirow[t]{2}{*}{ Statistical relation ( $t$-test) } \\
\hline & US positive & US negative & Controls & \\
\hline \multirow[t]{3}{*}{ Pyloric muscle thickness } & $5.41 \pm 0.91$ & $2.24 \pm 0.28$ & $2.2 \pm 0.27$ & $1-2: t=14.9, p<0.0001$ \\
\hline & & & & $1-3: t=18.7, p<0.0001$ \\
\hline & & & & $2-3: t=0.5, \mathrm{NS}$ \\
\hline \multirow[t]{3}{*}{ Pyloric diameter } & $14.1 \pm 1.47$ & $7.42 \pm 0.45$ & $7.48 \pm 0.54$ & $1-2: t=19.5, p<0.0001$ \\
\hline & & & & $1-3: t=23.7, p<0.0001$ \\
\hline & & & & $2-3: t=-0.4, \mathrm{NS}$ \\
\hline \multirow[t]{3}{*}{ Pyloric length } & $20.89 \pm 3.33$ & $12.73 \pm 2.02$ & $12.34 \pm 1.99$ & $1-2: t=10.2, p<0.0001$ \\
\hline & & & & $1-3: t=13.0, p<0.0001$ \\
\hline & & & & $2-3: t=0.6, \mathrm{NS}$ \\
\hline
\end{tabular}

SD - standard deviation, NS - not significant 


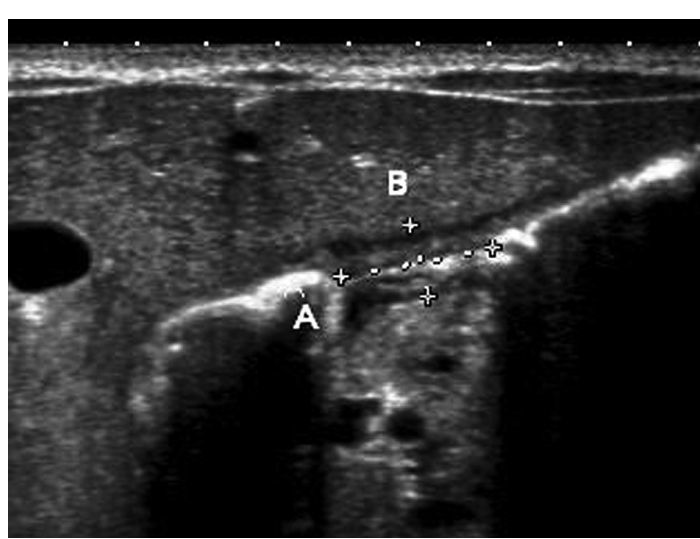

Figure 1. Ultrasonographic image of the normal pylorus in a 3-week-old female. A - indicates pyloric length $(12 \mathrm{~mm}), \mathrm{B}$ - pyloric diameter $(7 \mathrm{~mm})$

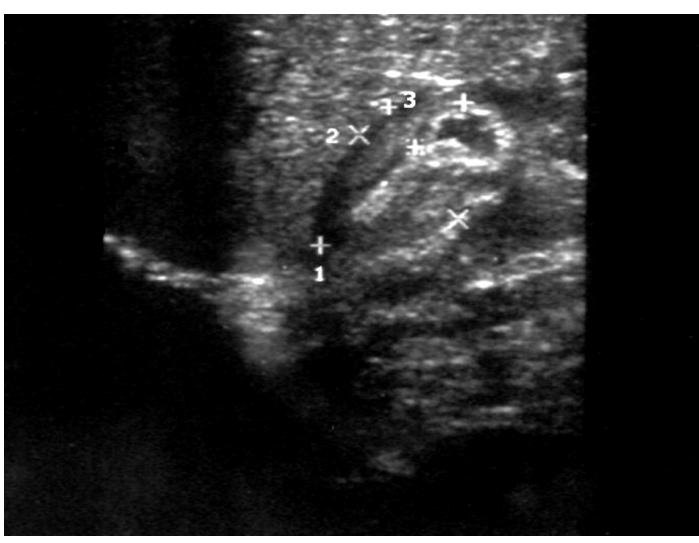

Figure 2. Ultrasonographic scan of the hypertrophic pylorus in a 5-week-old male. 1 - indicates pyloric length $(22.5 \mathrm{~mm}), 2$ - pyloric diameter $(14 \mathrm{~mm})$, 3 -pyloric muscle thickness (6 $\mathrm{mm})$

lower than $3 \mathrm{~mm}$ in infants with IHPS, and was never higher than $2.5 \mathrm{~mm}$ in children with negative diagnosis. The pyloric length was never higher than $15 \mathrm{~mm}$ in infants without IHPS and was never below $16 \mathrm{~mm}$ in children with a positive diagnosis.

The mean PL (12.34), PMT (2.2), and PD (7.48) in the reference group did not differ significantly from values obtained in patients with a negative IHPS diagnosis and were significantly lower than in children from the IHPS group $(p<0.0001)$ (Table II, Figures 1 and 2).

Ultrasound imaging had a sensitivity of $98 \%$ and specificity of $100 \%$, with a positive and negative predictive value of $100 \%$ and $90 \%$ respectively
(Table III). The two diagnostic false negative errors occurred at the beginning of the analysed period (the 'learning curve' of the sonographers) and never occurred later. There were no false positive US scans in this study. US scans were repeated in six children to confirm the diagnosis $(6 / 115-5 \%)$.

\section{Discussion}

Wide access to ultrasonography in the late 1980s began a new era in diagnostics of IHPS. Before diagnosis was based mainly on clinical criteria, such as palpation of the hard muscle mass of the pylorus and barium meal studies for problematic and equivocal cases. Ultrasound created new possibilities. The examination is easy to perform, is noninvasive and is simple and reliable if performed by an experienced paediatric sonographer. With increasing accuracy of sonography the usefulness and reliability of clinical examination declined to less than $50 \%$ in the early 1990 s and is probably even lower nowadays [12].

We noticed that the pyloric muscle was never thicker than $2.5 \mathrm{~mm}$ in patients without IHPS both in the examined and in the reference group. A pyloric muscle thickness greater than $3 \mathrm{~mm}$ was found in all cases of IHPS. Our findings were similar to those reported in the literature $[10,13,14]$. In infants with clinical symptoms of IHPS and borderline muscle thickness of $3 \mathrm{~mm}$ US examination should be repeated a few days later. Persistent vomiting usually causes dehydration of the infant with pyloric stenosis resulting in low measurements on sonographic scans. Starinsky et al. reported that the muscle thickness measurements increased in almost $50 \%$ of patients with IHPS after effective fluid resuscitation [15]. In our series, US examination was repeated after 3-4 days of observation in 6 infants with borderline measurements and persistent non-bilious vomiting after most feeding during a day. Pyloric stenosis was confirmed in all 6 precarious cases.

We found that the pyloric length was never below $17 \mathrm{~mm}$ in children with IHPS and was never greater than $15 \mathrm{~mm}$ in infants with a negative diagnosis. In children with borderline pyloric length of 15-16 mm this parameter should, in the authors' opinion, be considered only together with pyloric muscle thickness.

Table III. Sensitivity and specificity of ultrasonography (US) in the group of infants with hypertrophic pyloric stenosis (IHPS)

\begin{tabular}{|llccc|}
\hline US diagnosis of IHPS & \multicolumn{2}{c|}{ IHPS } & Predictive value \\
\cline { 2 - 4 } & & $(+)$ & $(-)$ & Positive $-100 \%$ \\
\hline US & $(+)$ & True positive -94 & False positive -0 & Negative $-90 \%$ \\
\cline { 2 - 5 } & $(-)$ & False negative -2 & Specificity $-100 \%$ & $\times$ \\
\hline
\end{tabular}


Some of the infants with IHPS are premature. However, no correlation has been reported in the literature between infant body weight and length and PMT measured in ultrasound [11, 12]. Haider et al. found that pyloric length in infants with IHPS was significantly greater in those born at term compared to those born prematurely and that PL was strongly correlated with the weight of the infant [11]. Godbole et al. did not confirm these findings [16].

An important sonographic sign is visualization of the passing of the gastric contents through the relaxing pyloric canal. If the sonographer notices this sign, a positive diagnosis of IHPS can be definitely excluded.

Ultrasound imaging as reported in the literature had sensitivity ranging from 76 to $100 \%$ and specificity from 85 to $100 \%$ [10, 13-15]. The results obtained in our series revealed a sensitivity of $98 \%$ and specificity of $100 \%$ of this diagnostic tool.

In conclusion, this study confirmed that ultrasound examination is the first choice of diagnostic method in an infant with suspected hypertrophic pyloric stenosis. In cases with an uncertain clinical diagnosis of IHPS the examination can be easily repeated and unnecessary surgery can thereby be prevented.

The US criteria for a positive diagnosis of infantile hypertrophic pyloric stenosis established with our study are pyloric muscle thickness (PMT) of $3 \mathrm{~mm}$ and above and pyloric muscle length (PML) of $17 \mathrm{~mm}$ and above.

\section{References}

1. Pedersen RN, Garne E, Loane M, Korsholm L, Husby S; EUROCAT Working Group. Infantile hypertrophic pyloric stenosis: a comparative study of incidence and other epidemiological characteristics in seven European regions. J Matern Fetal Neonatal Med 2008; 21: 599-604.

2. Applegate MS, Druschel CM. The epidemiology of infantile hypertrophic pyloric stenosis in New York State, 1983 to 1990. Arch Pediatr Adolesc Med 1995; 149: 1123-9.

3. Schechter R, Torfs CP, Bateson TF. The epidemiology of infantile hypertrophic pyloric stenosis. Paediatr Perinat Epidemiol 1997; 11: 407-27.

4. Sommerfield T, Chalmers J, Youngson G, Heeley C, Fleming $M$, Thomson $G$. The changing epidemiology of infantile hypertrophic pyloric stenosis in Scotland. Arch Dis Child 2008; 93: 1007-11.

5. Sule ST, Stone DH, Gilmour H. The epidemiology of infantile hypertrophic pyloric stenosis in Greater Glasgow area, 1980-96. Paediatr Perinat Epidemiol 2001; 15: 379-80.

6. Wang J, Waller DK, Hwang LY, Taylor LG, Canfield MA. Prevalence of infantile hypertrophic pyloric stenosis in Texas, 1999-2002. Birth Defects Res A Clin Mol Teratol 2008; 82: 763-7.

7. Donovan EJ. Hezekiah Beardsley, congenital hypertrophic stenosis of the pylorus. Arch Pediatr 1958; 75: 359.

8. Ramstedt C. Zur Operation der angeborenen Pylorusstenose. Med Klin 1912; 8: 1702.
9. Riccabona M. Sonography of hypertrophic pyloric stenosis - attempt at prognostic evaluation based on sonographic criteria. Wien Klin Wochenschr 1990; 102: 13-5.

10. Neilson D, Hollman AS. The ultrasonic diagnosis of infantile hypertrophic pyloric stenosis: technique and accuracy. Clin Radiol 1994; 49: 246-7.

11. Haider N, Spicer R, Grier D. Ultrasound diagnosis of infantile hypertrophic pyloric stenosis: determinants of pyloric length and the effect of prematurity. Clin Radiol 2002; 57: 136-9.

12. Macdessi J, Oates R. Clinical diagnosis of pyloric stenosis: a declining art. BMJ 1993; 306: 553-5.

13. Assefa G. Sonographic diagnosis of hypertrophic pyloric stenosis: preliminary experience. Ethiop Med J 2002; 40: 149-54.

14. Forster N, Haddad RL, Choroomi S, Dilley AV, Pereira J. Use of ultrasound in 187 infants with suspected infantile hypertrophic pyloric stenosis. Australas Radiol 2007; 51: 560-3.

15. Starinsky R, Klin B, Siman-Tov Y, et al. Does dehydration affect thickness of the pyloric muscle? An experimental study. Ultrasound Med Biol 2002; 28: 421-3.

16. Godbole P, Sprigg A, Dickson JA, Lin PC. Ultrasound compared with clinical examination in infantile hypertrophic pyloric stenosis. Arch Dis Child 1996; 75: 335-7. 